\title{
COMPARTILHAMENTO DE INFORMAÇÕES DE TRÂNSITO UTILIZANDO SMARTPHONES
}

\section{SHARING INFORMATION FROM TRAFFIC USING SMARTPHONES}

\author{
Bruno Pereira Trovo ${ }^{1}$; Almir Olivette Artero ${ }^{1}$; Marco Antonio Piteri ${ }^{1}$; \\ Francisco Assis da Silva² \\ ${ }^{1}$ UNESP - Universidade Estadual Paulista, Faculdade de Ciências e Tecnologia - FCT, \\ Presidente Prudente - SP, Brasil. E-mail: brunotrovo@hotmail.com, \\ almir@fct.unesp.br, piteri@fct.unesp.br. ${ }^{2}$ UNOESTE - Universidade do Oeste \\ Paulista, Faculdade de Informática - FIPP. E-mail: chico@unoeste.br
}

RESUMO - Este trabalho apresenta uma solução para um problema cotidiano das grandes cidades, o trânsito, utilizando smartphones como ferramenta. Esses dispositivos cada vez mais presentes no cotidiano das pessoas são a base para esta solução, visto que possuem funcionalidades como GPS e conexão de dados com a internet. Este trabalho apresenta a criação de um aplicativo para plataforma móvel Android que, tem em um primeiro momento, a função de enviar informações das condições de trânsito enfrentadas pelos usuários que estejam trafegando com o aplicativo em funcionamento. A partir dessas informações já enviadas pelos usuários do aplicativo e armazenadas em um banco de dados Web, é possível obter a partir do smartphone as condições de tráfego de um trajeto a ser percorrido.

Palavras-chave: Controle de Tráfego; Smartphone; GPS.

ABSTRACT - The aim of this work is to propose a solution to an everyday problem of big cities, traffic, using smartphones as a tool. These devices increasingly present in daily life are the basis for this solution, since they have features like GPS and data connection to the internet. This paper presents the creation of an application for Android mobile platform that, in a first moment, it has the function of sending information on traffic conditions faced by users who are traveling with the application running. From these information already sent by application users and stored in a Web database, it is possible to get the traffic conditions of a path to be traversed from smartphone.

Keywords: Traffic Control; Smartphone; GPS. 


\section{INTRODUÇÃO}

De acordo com a FENABRAVE (Federação Nacional da Distribuição de Veículos Automotores) (FENABRAVE, 2013), apenas no primeiro mês do ano de 2013 foram emplacados 296.583 veículos (automóveis de passeio e comerciais leves), ou seja, em apenas um mês quase 300.000 novos veículos foram acrescentados ao trânsito nacional, sendo que $48,81 \%$ foram para a região Sudeste do País. Somam-se ainda a este mesmo mês 14.604 caminhões e ônibus, e ainda 126.404 motos, disputando dia a dia o espaço nas ruas. É inevitável que devido a tal quantidade de veículos o trânsito passe a ser um problema, tendo em vista que a infraestrutura não consegue evoluir tão rapidamente quanto o aumento da quantidade de veículos nas ruas. Principalmente, em grandes cidades, como em São Paulo no Brasil, tem se tornado comum aos motoristas ficar horas em filas, 0 que parece ser um problema sem uma solução imediata, que gera muitos prejuízos financeiros e, principalmente, prejuízos relativos à qualidade de vida das pessoas envolvidas, sendo estes imensuráveis.

Nos dias atuais o monitoramento do trânsito é feito de forma convencional, com o uso de câmeras de vídeo e centrais de monitoramento. Em São Paulo, por exemplo, o tráfego é monitorado pela CET (Companhia de Engenharia de Tráfego), a qual é subordinada à Secretaria de Transportes, que efetua o monitoramento utilizando-se de aproximadamente 300 câmeras de vídeo e duas centrais de monitoramento, para um total de $15.546 \mathrm{~km}$ de vias (CET, 2013). O congestionamento observado diariamente mostra que este monitoramento não tem sido suficiente, tendo em vista tal quantidade de veículos e tamanha extensão de vias.

Nos últimos anos, aparelhos de GPS e serviços de mapa e localização (como o Google Maps) têm facilitado o deslocamento dos usuários permitindo a escolha de rotas baseadas em possíveis caminhos que podem ser percorridos. Por se tratar de uma tecnologia presente também nos atuais smartphones, a combinação de GPS e conectividade com a internet pode se tornar uma aliada no fornecimento de informações de trânsito. Assim, este trabalho tem por objetivo apresentar um meio colaborativo para o fornecimento de informações relacionadas às condições de trânsito em que o usuário está inserido. A partir destas informações deverá ser possível monitorar as condições de trânsito através da colaboração dos usuários, de modo independente da infraestrutura convencional, além de constituir um meio de abastecimento de informações quando a infraestrutura baseada em câmeras for insuficiente. Adicionalmente é possível que o usuário veja quais as condições de trânsito de uma rota selecionada por ele e, caso as condições não sejam favoráveis, o usuário poderá então selecionar uma 
rota alternativa buscando condições favoráveis. As demais seções deste trabalho estão organizadas da seguinte maneira: Inicialmente, na Seção 2 é apresentado sucintamente o tema colaboração e compartilhamento de informação, bem como uma revisão dos conceitos relacionados ao Sistema de Posicionamento Global (GPS), suas variações e equipamentos. Ainda nessa seção é mostrada a integração entre sistemas de GPS e aparelhos smartphone, os conceitos técnicos relacionados ao desenvolvimento, apresentando os conceitos do sistema operacional e plataforma de desenvolvimento Android, sobre a qual este trabalho foi desenvolvido. Nessa seção também são mostrados alguns recursos técnicos utilizados no trabalho, tais como as APIs fornecidas pelo Google, que apoiam o desenvolvimento na plataforma Android; $\mathrm{Na}$ Seção 3 são apresentados os trabalhos relacionados, que serviram de inspiração à abordagem deste trabalho. A Seção 4 detalha passo-a-passo a proposta apresentada neste trabalho, ilustrando de forma clara e detaIhada o funcionamento dos módulos desenvolvidos; Na Seção 5 são discutidos alguns experimentos feitos com o sistema em funcionamento, de modo a ilustrar a sua aplicação em campo; Por fim, a Seção 6 apresenta as conclusões finais obtidas neste trabalho e sugere ainda linhas a serem seguidas em trabalhos futuros.

\section{FUNDAMENTAÇÃO TEÓRICA}

Esta seção apresenta as tecnologias e conceitos que dão suporte ao desenvolvimento deste trabalho: A colaboração, base para obtenção das informações; Tecnologias de localização GPS; e a plataforma Android, sobre os quais é construída a aplicação produto deste trabalho.

\subsection{A Colaboração e Compartilhamento de Informação}

A formação de grupos de pessoas e consequente colaboração ocorrem quando há a necessidade de execução de uma tarefa que seja ou muito grande, ou muito complexa ou que dependa de várias competências, sendo necessária a união de pessoas em prol de uma causa única. Grupos para colaboração podem ser formados de forma espontânea quando um indivíduo percebe a necessidade de se juntar a um ou mais indivíduos em busca de um objetivo comum. Por outro lado, grupos podem ser formados a partir da iniciativa de uma entidade externa, a qual identifica uma necessidade, estabelece as características que o grupo precisa ter e faz a seleção dos participantes, apresentando-os uns aos outros, culminando na criação do grupo com o mesmo propósito (VIVACQUA; GARCIA, 2011). Um grupo com o mesmo propósito pode então usar o conhecimento coletivo como meio para atingir o seu objetivo. $\mathrm{O}$ conhecimento coletivo, caracterizado como a 
união e a combinação dos conhecimentos de indivíduos que formam este grupo, é a base para a solução de problemas complexos atuais. Habilidades, conhecimento e experiências individuais são unidas de modo a obter diferentes ideias e pontos de vistas para a resolução do problema em comum. A união e mescla do conhecimento coletivo pode ser feita de várias formas, tais como entrevistas, dinâmicas de grupo ou dinâmicas de grupo apoiadas por sistemas computacionais, sendo que tais sistemas eliminam a necessidade de que os participantes estejam ao mesmo tempo no mesmo local (BORGES, 2011).

A Wikipédia é uma referência em termos de colaboração na atualidade. Tendo como slogan a frase "Wikipédia: Enciclopédia Livre", a Wikipédia é um projeto de enciclopédia baseado na Web, multilíngue, de licença livre e escrita de maneira colaborativa. Ou seja, com algumas exceções tais como páginas propensas a vandalismo, qualquer artigo pode ser editado de forma anônima ou por usuário cadastro. Edições em diferentes idiomas podem alterar esta política. Em língua inglesa, por exemplo, apenas usuários cadastrados podem criar um novo artigo. Apenas para ressaltar a confiabilidade do conteúdo, em pesquisa conduzida em 2005 constatouse que a precisão de artigos científicos aproximava-se da precisão da Enciclopédia Britânica (WIKIPÉDIA, 2013).
Outro exemplo de colaboração, porém, este muito mais sutil encontra-se no sistema de tradução do Google, o Google Tradutor. Ao fazer a pesquisa por uma tradução, caso esta pareça estar incorreta, é provável que outras traduções para o mesmo termo estejam disponíveis e caso não haja, é possível ainda sugerir uma nova tradução. Ao selecionar outra tradução ou sugerir uma nova, o tradutor automaticamente aprende com a sua informação e melhora ao longo do tempo para futuras pesquisas feitas pelo mesmo ou por outro usuário (GOOGLE TRANSLATOR, 2013). Há ainda outro exemplo de colaboração, que funciona sem a intervenção do usuário. O World Community Grid é um projeto de computação distribuída voltado para o processamento de pesquisas humanitárias. O processo é muito simples: o usuário faz o download e instala em seu computador o software fornecido pelo World Community Grid. Quando o computador do usuário ficar ocioso, o software automaticamente passa a utilizar $60 \%$ da capacidade de processamento da máquina para o processamento de dados de pesquisa científica. Uma vez que o usuário volte a usar o computador, o processamento de pesquisa é interrompido e reinicia-se quando o computador ficar ocioso novamente (KAPLAN, 1996). Esses são exemplos de colaboração que podem ou não exigir a intervenção constante do usuário, mas que tem sempre como objetivo 
ajudar uma causa que vá servir à sociedade ou determinado grupo de pessoas.

\subsection{GPS - Sistema de Posicionamento Global}

Na década de 70 surgiu nos Estados Unidos a proposta conhecida como NAVSTAR-GPS (Global Positioning System), um sistema que revolucionou as atividades que eram dependentes da determinação de posições sobre o globo terrestre. Ao mesmo tempo, na antiga URSS foi desenvolvido o GLONASS (Global Orbitting Navigation Satellite System), sendo este muito similar ao NAVSTAR-GPS. Já no final de década de 90, a Agência Espacial Europeia propôs o desenvolvimento do sistema de navegação Galileo, o qual se encontra em desenvolvimento. Esses sistemas são chamados, de uma forma geral, de GPS Sistema Global de Navegação por Satélite ou GNSS (Global Navigation Satellite System). O GPS, como é comumente conhecido o NAVSTAR-GPS, foi desenvolvido pelo DoD (Departement of Defense) e tinha como objetivo, ser o principal sistema de navegação das forças armadas norteamericanas. Entretanto, hoje o GPS é utilizado nos mais diversos segmentos da comunidade civil (Navegação, posicionamento geodésico, agricultura, logística, etc.).

\subsubsection{Composição do GPS}

O sistema GPS é composto de três segmentos: Segmento Espacial, Segmento de
Controle e Segmento de Usuários (KAPLAN, 1996). O primeiro segmento, o Espacial, consiste de no mínimo 24 Satélites MEO (Medium Earth Orbits), distribuídos em seis planos orbitais igualmente espaçados, com quatro satélites em cada plano, posicionados em uma altitude de $20.200 \mathrm{~km}$. Os planos orbitais são inclinados $55^{\circ}$ em relação ao Equador e o período orbital é de aproximadamente 12 horas siderais. Sendo assim, a posição dos satélites se repete, a cada dia, aproximadamente quatro minutos antes em relação ao dia anterior. Desse modo, garante-se que no mínimo quatro satélites estarão visíveis em qualquer local da superfície terrestre, a qualquer hora por um receptor GPS. A Figura 1 apresenta uma representação gráfica do posicionamento dos satélites GPS ao redor do planeta.

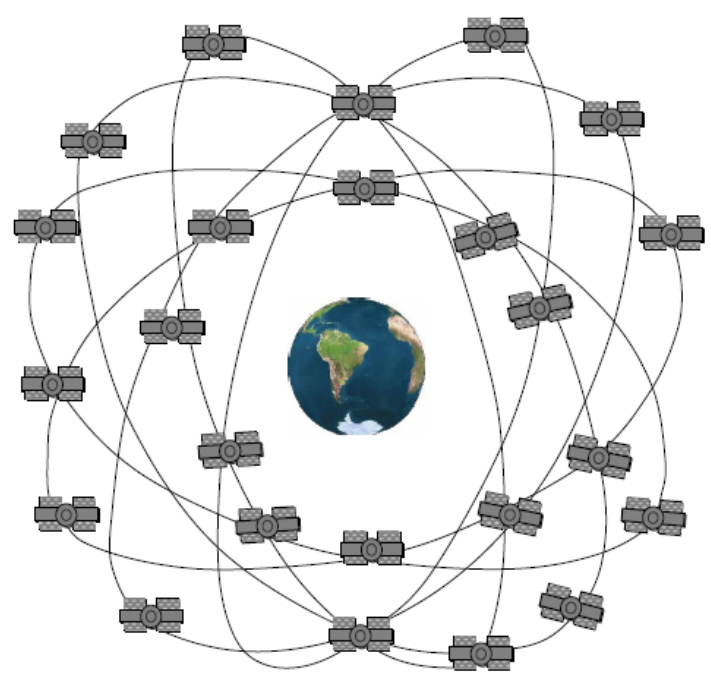

Figura 1. Constelação de satélites GPS. Fonte: (MONICO, 2000).

O Segmento de Controle é composto por cinco estações monitoras, localizadas em: 
Colorado Springs, Hawaii, Ascension Island, Diego Garcia e Kwajalein, sendo as três últimas, com antenas para a transmissão de dados para os satélites, e uma estação de controle central (MCS - Master Control Station) localizada em Colorado Springs. Em conjunto a essas estações pertencentes à Força Aérea Americana, estão outras sete da NGA (National Geospatial-Intelligence). Este conjunto de estações compõe as estações monitoras GPS do DoD, e têm como principais tarefas (MONICO, 2008):

- Monitorar e controlar continuamente o sistema de satélites;

- Determinar o sistema de tempo GPS;

- Predizer as efemérides dos satélites, calcular as correções dos relógios dos satélites;

- Atualizar as mensagens de navegação de cada satélite periodicamente.

O último dos segmentos é o segmento de Usuário, que se fundamenta nos receptores GPS, que variam bastante em suas especificações técnicas, podendo ou não estar agregados a outros dispositivos, mas sempre possuindo os requisitos básicos para a recepção do sinal GPS. De modo simplificado, os principais componentes de um receptor são (MONICO, 2008):

- Antena com pré-amplificador;

- Seção de RF (radiofrequência) para identificação e processamento do sinal;
- Microprocessador para controle do receptor, amostragem e processamento dos dados;

- Oscilador;

- Interface para usuário com painel de exibição e comandos;

- Provisão de energia;

- Memória para armazenamento dos dados.

Os três seguimentos citados anteriormente, Segmento Espacial, Segmento de Controle e Segmento de Usuários, são os responsáveis pelo funcionamento do sistema GPS.

\subsubsection{Funcionamento}

A concepção do sistema GPS permite que um usuário em qualquer ponto próximo da superfície terrestre esteja apto a receber sinais de pelo menos quatro satélites sob quaisquer condições climáticas, sendo que o princípio de funcionamento da navegação pelo sistema de GPS consiste na medida de distâncias entre o usuário e quatro satélites (Figura 2) (MONICO, 2008). O GPS foi projetado para trabalhar ao ar livre, ou seja, fora de prédios ou outros obstáculos que possam dificultar a recepção do sinal, pois além do sinal ser extremamente fraco, o conjunto de satélites encontra-se a uma distância de aproximadamente $20.000 \mathrm{~km}$ de altura. Desenvolvido para longos períodos de uso, o GPS necessita de um tempo para ser iniciado 
pela primeira vez, conhecido como "first time to fix", o qual representa o tempo necessário para adquirir o sinal de satélite, receber e decodificar os dados do satélite, dados estes que representam a órbita e o tempo em que cada um dos satélites se encontra. Assim, o que ocorre na verdade é que o usuário é quem rastreia a posição dos satélites, e não o contrário.

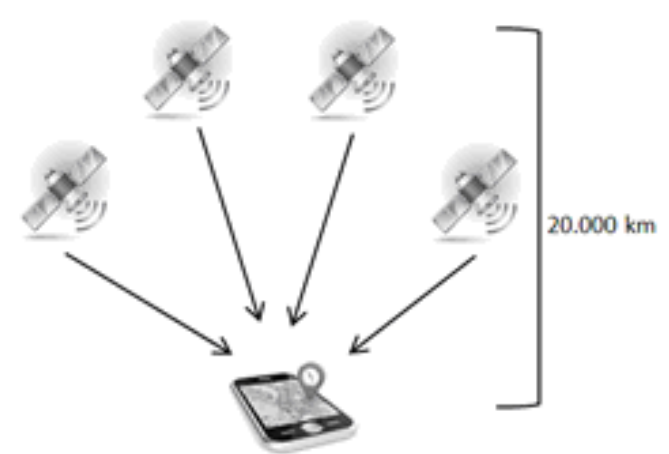

Figura 2. Ilustração da Visibilidade de um Dispositivo GPS. Fonte: (MONICO, 2008).

O cálculo básico da posição ocorre da seguinte maneira (DIGGELEN, 2009):

- Medição das distâncias do receptor até os diversos satélites;

- Cálculo da posição dos satélites usando os dados recebidos;

- Resolução das equações envolvendo a posição dos satélites, distâncias e tempos, resultando na posição do receptor.

Notam-se duas limitações no funcionamento do GPS, a baixa intensidade do sinal e o tempo gasto com a aquisição de sinal e decodificação dos dados recebidos do satéli- te para o cálculo da posição inicial. Essas limitações são superadas com o GPS Assistido, A-GPS (Assisted-GPS), e são brevemente explicadas a seguir.

\subsubsection{A-GPS}

Antes que um GPS possa fazer os cálculos necessários para obter a sua posição, este deve adquirir os sinais de satélite. Porém, antes que os sinais de cada satélite possam ser obtidos, o receptor deve encontrar outras informações necessárias, como a correta frequência para cada satélite e o código de atraso de sinal (code delay). Uma vez que o sinal tenha sido adquirido, um GPS convencional (sem assistência) deve decodificar o tempo de envio e os dados contendo a órbita do satélite e modelos de clock. Todas essas informações são necessárias para que o receptor GPS possa se localizar inicialmente. Este processo para obtenção da primeira localização leva cerca de um minuto, mas possui um agravante, caso ocorra uma perda de sinal, o que é muito comum, pois neste caso, todo o processo se inicia novamente, sendo comum este processo de aquisição levar vários minutos para se completar.

Neste ponto coloca-se a principal ideia do GPS-Assistido, que é fornecer toda a informação possível através de algum meio alternativo, como por exemplo, uma conexão de dados utilizando sinal de torres de telefonia celular. As informações necessárias para 
a obtenção inicial de posição são obtidas e armazenadas em um servidor do operador da rede. O receptor A-GPS conecta-se a esses servidores e faz o carregamento dessas informações através de redes tais como GSM, CDMA, WCDMA, LTE ou WI-FI. Essa transmissão é feita de forma muito mais rápida, pois tipicamente a velocidade de transmissão de dados dessas portadoras é alta.

A tecnologia de GPS Assistido pode ser dividida ainda em duas grandes abordagens: Estação móvel assistida (MSA) e Estação móvel baseada (MSB). Na primeira, a MSA, o dispositivo portado pelo usuário pode receber assistência de aquisição, tempo de referência e outros dados de assistência opcional a partir do servidor de dados A-GPS. O dispositivo usa esses dados para então receber os sinais dos satélites visíveis e enviar as medições para o servidor A-GPS. Em seguida a posição é calculada pelo servidor e enviada de volta para o dispositivo do usuário. Já na segunda abordagem, a MSB, o processo de assistência se repete, porém, o cálculo da distância é feito no próprio dispositivo ao invés de ser feito no servidor A-GPS (DIGGELEN, 2009).

\subsection{Sistema Operacional Android}

O Android é uma plataforma de desenvolvimento para aplicativos móveis, baseada no sistema operacional Linux, conta com aplicações pré-instaladas e um ambiente de desenvolvimento, o qual possui hoje uma vasta comunidade de desenvolvedores, tendo se tornado a principal plataforma de desenvolvimento para dispositivos móveis.

Por trás do Android está a Open Handset Alliance (2013), um grupo formado por gigantes do mercado liderados pelo Google. As empresas LG, Motorola, Samsung, Sony Ericsson, ASUS, Intel e Dell são apenas alguns dos integrantes desse grupo, cuja lista completa pode ser encontrada em: www.openhandsetalliance.com/oha_member s.html.

O sistema operacional Android foi baseado no kernel 2.6 do Linux, responsável por gerenciar a memória, os processos, threads, segurança de arquivos e pastas, redes e drivers. As aplicações para o sistema operacional Android são construídas utilizando-se a linguagem de programação Java. O códigofonte depois de compilado em Java, dando origem a um arquivo bytecode (.class), é convertido para o formato .dex (Dalvik Executable). A partir deste ponto a máquina virtual Dalvik compacta os arquivos .dpk necessários junto a outros recursos necessários em um arquivo Android Package File (.apk), esse arquivo é a aplicação final, pronta para ser distribuída e instalada. Além disso, a plataforma Android é livre e de código aberto, sendo que qualquer desenvolvedor pode desenvolver aplicações voltadas para a mesma. Outra vantagem, dessa vez para os fabri- 
cantes de dispositivos, é que a licença Apache Software Foundation (ASF) permite que alterações sejam feitas no código-fonte para a criação de produtos customizados, sem que essas alterações tenham que ser compartiIhadas (LECHETA, 2013).

\subsubsection{Google APIs}

Para auxiliar o desenvolvimento de aplicações para a sua plataforma, o Google fornece uma vasta gama de APIs. Uma API (Application Programming Interface) caracteriza-se como um conjunto de rotinas, funções e padrões já desenvolvidos e estabelecidos por um software para a utilização de suas funcionalidades. Dentre os conjuntos de API fornecidos pelo próprio Google pode-se citar, por exemplo: API para manipulação da câmera integrada e de mídia, API para uso de recursos de conectividade, API de Localização e Sensores, e muitas outras. A API de localização, por exemplo, permite que detalhes de implementação sejam abstraídos, e rotinas já implementadas sejam utilizadas. Assim, questões como desempenho, consumo de bateria, ou manipulações de baixo nível não precisam ser levadas em consideração na maior parte do desenvolvimento (GOOGLE ANDROID DEVELOPERS, 2013).

\section{TRABALHOS RELACIONADOS}

Por se tratar de um problema comum ao redor do mundo, a captação de informa- ções de trânsito e sua posterior manipulação já foram o assunto de diversos trabalhos $\mathrm{e}$ mesmo projetos comerciais. As abordagens até então mais utilizada fazem uso de infraestrutura composta por câmeras, contadores de veículos e sensores, usados em pontos estratégicos para obtenção dessas informações. Alguns ainda mais avançados, como fazem uso da tecnologia de RFID (RadioFrequency IDentification) para leitura e obtenção de dados (SALAMA, 2010).

Em Bauza (2010) é proposto um método de cooperação veicular, baseado em comunicações Veículo para Veículo, ou V2V, usando Lógica Fuzzy para a detecção de congestionamentos. Esta abordagem, porém, implica na necessidade de veículos capazes de realizar tal comunicação, sendo que tal capacidade ainda está longe de ser uma unanimidade nos veículos atuais. Outro projeto similar, porém este um sistema comercial, encontrado em ZAP (2013) apresenta um sistema que pode ser instalado em um GPS convencional. O sistema visa informar o motorista sobre as condições de trânsito próximas a este e funciona com a transmissão dos dados relacionados às condições de trânsito via ondas de rádio. Por se tratar de transmissão por ondas de rádios, a necessidade de instalação de uma antena adicional no veículo acaba se tornando um ponto negativo do sistema. Outro ponto negativo é que as informações são provenientes de uma compa- 
nhia de trânsito, a qual depende de infraestrutura inteligente que nem sempre é suficiente, e a transmissão das informações depende de uma emissora de rádio, por se tratar de uma aplicação comercial.

Em Waze (2013), é mostrado o Waze, uma comunidade para compartilhamento de informações de trânsito, já estabelecida e com grande número de usuários. O Waze baseia-se também no uso de smartphones e GPS para o compartilhamento de informações. Além disso, permite uma atitude proativa do usuário, podendo este informar sobre acidentes e outros problemas ao percorrer a sua rota. Um ponto importante no que diz respeito ao anonimato, é que por utilizar informações de posição e preferências de usuário, o Waze guarda informações de identificação do usuário em seus servidores, podendo comprometer o anonimato no uso da aplicação.

\section{PROPOSTA}

O desenvolvimento deste trabalho e da aplicação resultante pode ser dividido em duas etapas para melhor entendimento. A primeira etapa consiste na obtenção dos dados de trânsito a partir do GPS ou A-GPS presente no dispositivo. Enquanto o dispositivo se move, este recebe constantes atualizações com as coordenadas geográficas que representam sua posição. Para cada nova atualização recebida, o dispositivo imediatamente envia essas informações pela internet para um servidor através da rede de dados móveis. Uma vez recebidas pelo servidor, essas informações são armazenadas em um banco de dados para consultas. Na segunda etapa, um usuário qualquer faz uma solicitação de rota através do dispositivo, informando ponto de origem e destino. A obtenção da rota é feita através de uma requisição a um servidor do Google Maps, e este por sua vez retorna a rota em forma de segmentos de reta (par de coordenadas geográficas). Ao receber essas informações, o dispositivo as envia a outro servidor, verifica se houveram leituras recentes nos caminhos que compõe a rota, caso haja leituras, o servidor calcula a velocidade média de tráfego em cada segmento desta rota e retorna ao dispositivo. No dispositivo, essas informações são visualizadas no mapa de acordo com um esquema de cores prédefinido.

\subsection{Envio de Informações}

Desenvolvida sobre a plataforma Android, a aplicação faz uso das funcionalidades de GPS para obtenção de informações geográficas, e de conexões com a Internet para a transmissão dos dados obtidos. A Figura 3 mostra a tela inicial da aplicação, a qual apresenta um simples mapa com a posição inicial do usuário. A aplicação requer que a funcionalidade de GPS e conexão de dados sejam ativadas previamente. 


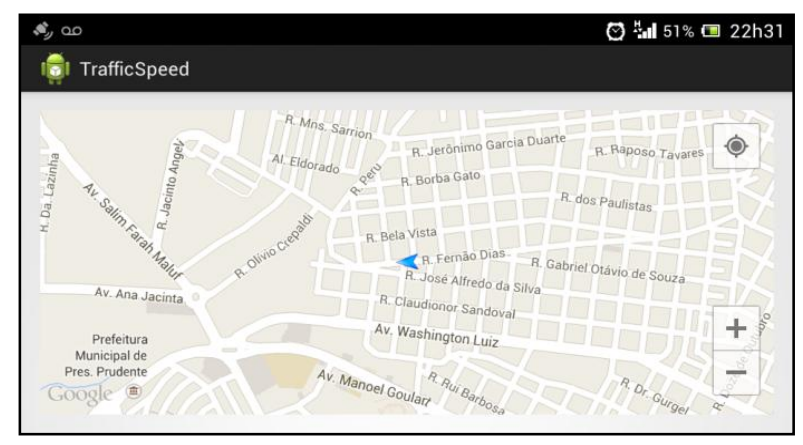

Figura 3. Tela inicial da aplicação.

A partir do momento em que o usuário começa a se mover, a aplicação passa a receber as informações do GPS. A API de Mapas do Google encapsula os métodos permitindo a manipulação dessas informações de forma mais simples, como o método "onLocationChaged (...)", responsável por informar ao dispositivo que houve uma mudança na posição do usuário. A partir do método citado anteriormente é possível extrair de forma direta as medidas de latitude, longitude, velocidade atual, e algumas outras informações provenientes do sistema GPS que não são usadas neste momento. É possível ainda configurar intervalos mínimos de tempo ou distância para que o usuário receba essas atualizações do GPS, visando principalmente a economia de bateria. Assim, supondo que seja configurado um intervalo de 50 metros, o dispositivo passa a receber as atualizações do GPS depois que este tenha percorrido uma distância em torno de 50 metros, evitando que atualizações desnecessárias sejam recebidas. Para facilitar o entendimento, a aplicação foi feita de modo a marcar o per- curso percorrido enquanto o usuário se desloca, utilizando cores diferentes de acordo com a velocidade obtida nas medições. $\mathrm{Na}$ Figura 4 pode-se ver o caminho demarcado utilizando as cores vermelho, amarelo, verde e azul. A seta azul identifica a posição corrente do usuário.

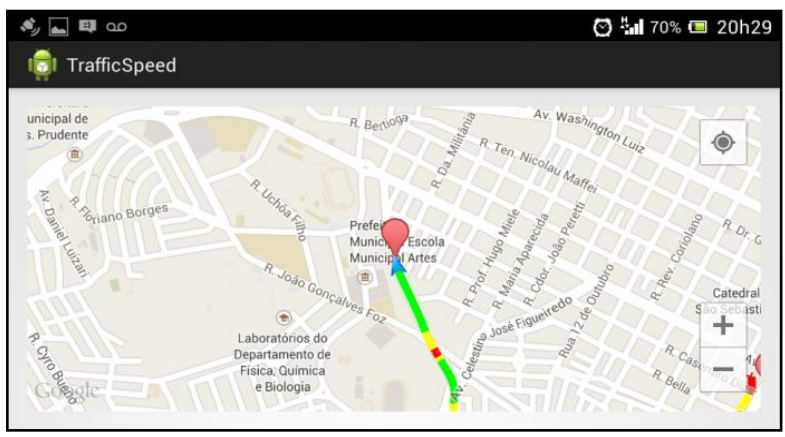

Figura 4. Trajeto obtido de acordo com a velocidade atual.

O significado de cada cor é apresentado na Tabela 1. Tais velocidades podem ser definidas com diferentes valores, caso seja necessário.

Tabela 1. Relação Cor x Velocidade.

\begin{tabular}{|c|c|}
\hline Cor & Velocidade \\
\hline Vermelho & Até $18 \mathrm{~km} / \mathrm{h}$ \\
\hline Amarelo & Entre $18 \mathrm{Km} / \mathrm{h} \mathrm{e} 36 \mathrm{Km} / \mathrm{h}$ \\
\hline Verde & Acima $36 \mathrm{Km} / \mathrm{h}$ \\
\hline Azul & Leituras Inexistentes ou fora de Alcance \\
\hline
\end{tabular}

A escolha dessas cores foi feita tendo como inspiração as cores utilizadas nos semáforos que controlam o trânsito, sendo que seus significados são obviamente conhecidos pelos usuários das vias. Durante o trajeto mostrado na Figura 4, as informações obtidas foram enviadas para um servidor Web através da conexão de dados e inseridas em um 
banco de dados SQLite do próprio dispositivo para transmissão posterior em caso de falha ou falta de conexão de dados. É importante lembrar que as informações coletadas e enviadas são completamente anônimas e não são capazes de levar a identificação do usuário que enviou os dados.

As informações transmitidas são recebidas por um servidor implementado utilizando a linguagem de programação PHP. As informações de latitude, longitude, velocidade e data atual, são inseridas diretamente em um banco de dados MySQL, não sendo necessário nenhum tipo de processamento dessas informações.

Como a colaboração é parte essencial deste trabalho, é importante que as informações obtidas possam ser disponibilizadas de forma aberta, sendo esta uma das razões pela qual nenhuma informação pessoal, ou que possa levar a identificação do usuário é coletada pelo aplicativo. Sendo assim, iniciativas públicas ou privadas poderiam utilizar essas informações como apoio, desde que o produto obtido com essas informações seja disponibilizado de forma aberta, e sem custos. Resumidamente, a primeira parte da aplicação é responsável por acompanhar a rota do usuário e enviar as informações rela- tivas às condições enfrentadas no tempo corrente para um servidor, o qual por sua vez as armazena em um banco de dados MySQL. Essas informações serão utilizadas por usuários que possam vir a solicitar uma rota que passe pelos mesmos caminhos.

\subsection{Solicitação de Rota}

A segunda etapa deste trabalho depende do processo colaborativo de fornecimento de dados executado anteriormente, pois a solicitação de uma rota fará uso dos dados enviados previamente por outros usuários que tenham passado pelos locais que compõe a rota solicitada, dados estes já armazenados no servidor.

Ao fazer a solicitação de uma rota, o usuário escolhe qual será o seu ponto de origem e de destino, sendo que normalmente a sua localidade atual é utilizada como ponto de partida. Nesse momento, é feita uma solicitação via Internet, utilizando a API do Google Maps (GOOGLE ANDROID DEVELOPERS, 2013) para os servidores exclusivos do Google. A chamada utiliza a seguinte URL (Uniform Resource Locator) padrão para solicitação de rotas, cujos parâmetros são obtidos conforme apresentado na Figura 5. 


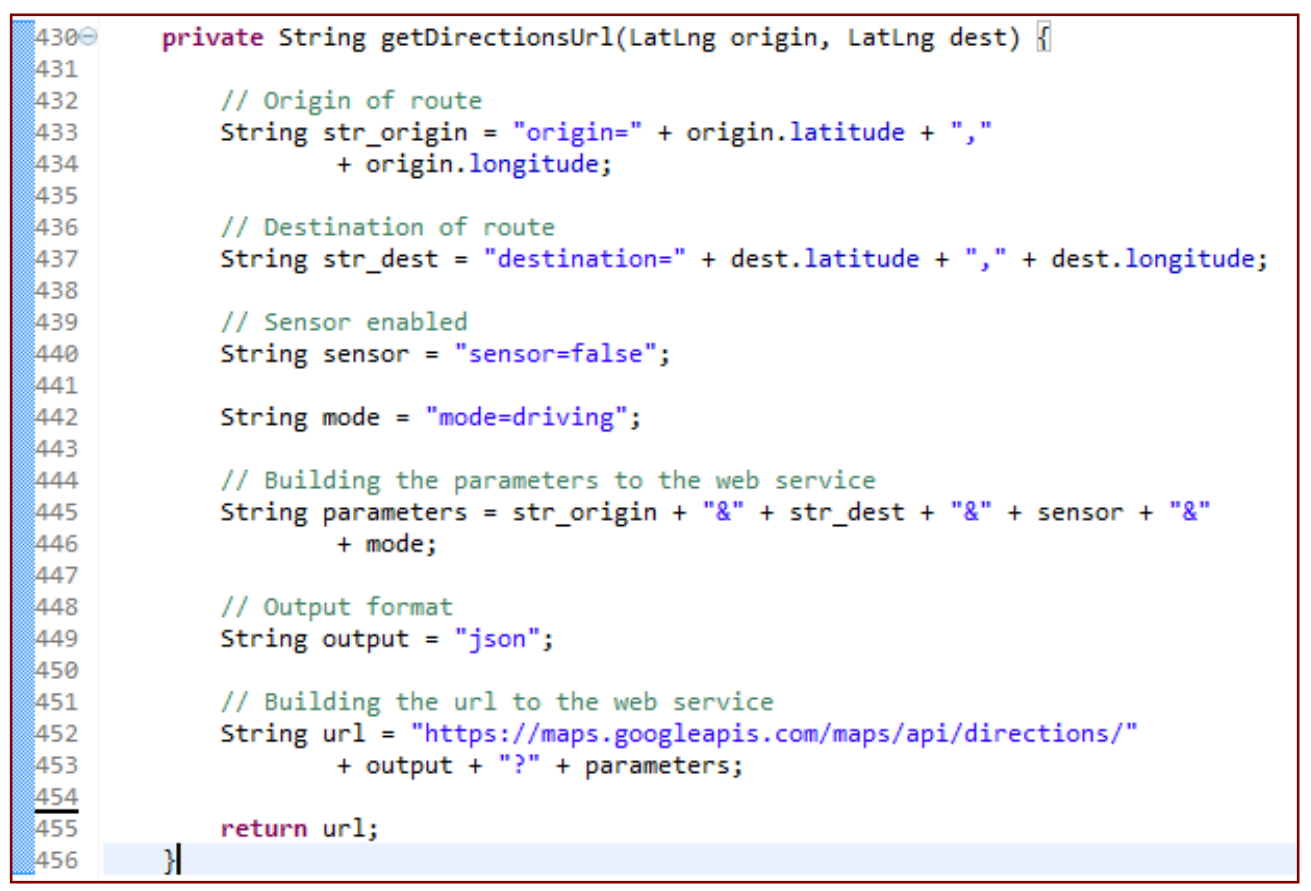

Figura 5. Criação da URL de solicitação de Rota.

A resposta a esta solicitação retorna em forma de um objeto, o qual pode ser um objeto XML (eXtensible Markup Language), ou um objeto do tipo JSON (JavaScript Object Notation), sendo esta última a escolhida na implementação deste trabalho, por se tratar de uma formatação leve para a troca de dados. O objeto de resposta contém todas as coordenadas geográficas que compõe a rota obtida, unindo origem e destino fornecidos pelo usuário. Ligando essa sequência de coordenadas através de segmentos de reta obtém-se a rota desejada no mapa do dispositivo. A Figura 6 mostra um exemplo de rota obtida pelo Google Maps por meio da solicitação exposta anteriormente. Este dois pontos são unidos por uma rota estabelecida sem nenhum critério, ou seja, sem a intervenção do aplicativo elaborado neste trabaIho. Ou seja, esta é a rota padrão que seria retornada para o usuário no smartphone sem o uso da aplicação.

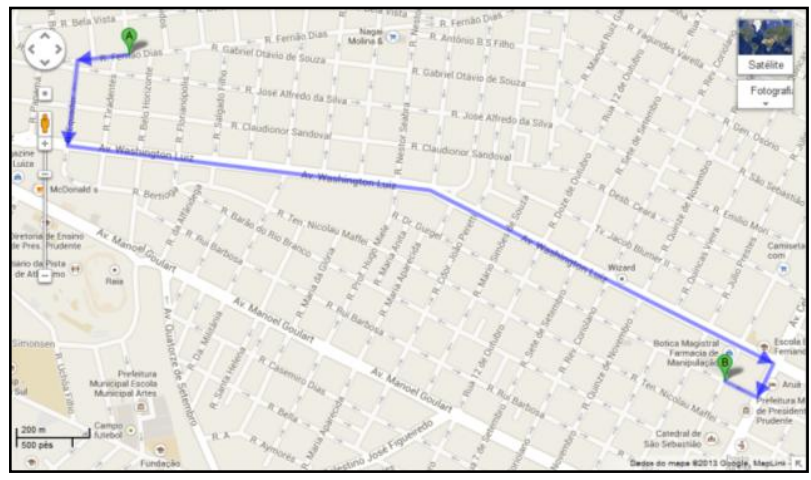

Figura 6. Rota estabelecida pelo Google Maps.

A partir do momento em que o objeto (JSON ou XML) contendo as coordenadas que compõe a rota é obtido, antes de representar o caminho no mapa, o dispositivo faz sucessivas consultas ao servidor PHP, enviando segmento por segmento, para obter a velocidade média daquele segmento, sendo possível identificar pontos de lentidão ou congestionamento, e partir de então utilizar outro 
caminho. As consultas são feitas no mesmo servidor PHP que foi utilizado anteriormente para o armazenamento destas informações no banco de dados MySQL, e o processo desenvolve-se da maneira relatada na sequência. Após o recebimento das coordenadas que compõe a reta, estas são enviadas aos pares, de forma sequencial para o servidor, sendo que cada par de coordenadas caracteriza um segmento de reta. Ou seja, se forem retornadas $n$ coordenadas, estas serão enviadas na forma $(n, n+1)$.

Para cada par de coordenas, o servidor faz uma busca no banco de dados e retorna os registros que foram obtidos em distâncias próximas, utilizando uma distância mínima configurável como parâmetro. Assim, todas as leituras feitas nas proximidades deste segmento de reta serão retornados e farão parte do cálculo da velocidade media registrada neste trecho. A velocidade média é calculada no servidor, utilizando a equação de distância mínima entre um ponto $P$ e um segmento de reta $r$, mostrada na Equação 1, onde $a, b$, e $c$ são os parâmetros da reta $r=a x+b x+c$, e são as coordenadas do ponto $P$.

$$
d=\frac{\left|a x_{0}+b y_{0}+c\right|}{\sqrt{a^{2}+b^{2}}}
$$

A velocidade média calculada é então retornada ao dispositivo, o qual utiliza este valor para determinar a cor com a qual será desenhado o segmento de reta em questão. Foram utilizadas cores baseadas no sistema de sinalização de trânsito, cores com as quais o usuário já está familiarizado. Tornando-se esta, uma representação visual de fácil entendimento das condições de cada parte do trajeto. Na Figura 7 pode-se ver o desenho de uma rota de testes, que de acordo com as velocidades obtidas pelo servidor enquanto o dispositivo se movia, são exibidas no mapa as retas de acordo com a cor correspondente.

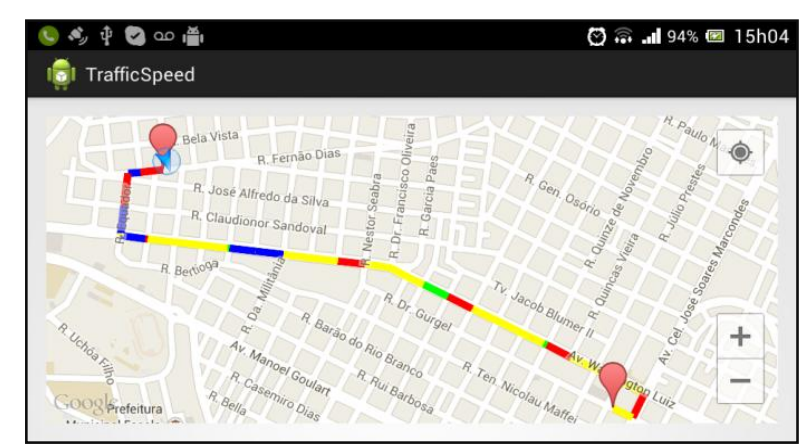

Figura 7. Rota com os trechos coloridos, de acordo com as velocidades obtidas.

Neste ponto, todo o processo da aplicação já foi percorrido. Dados já foram enviados, armazenados e processados para se tornarem critérios de ponderação dos segmentos do trajeto apresentado.

\section{EXPERIMENTOS}

Nesta seção são apresentados os resultados obtidos através do uso da aplicação utilizando dados coletados através do deslocamento do dispositivo por ruas da cidade.

O experimento foi realizado nas ruas da cidade de Presidente Prudente, São Paulo - Brasil, deslocando o dispositivo dentro de um veículo. Para este experimento foi utilizado um aparelho Smartphone Sony Xperia U, 
com um processador de $1 \mathrm{GHz}$ Dual Core, memória RAM de 512 MB e cartão de memória adicional de 8 GB (Figura 8). Esse aparelho possui um sistema A-GPS para obtenção das localizações, e conexão com a internet via rede de dados, ou via WIFI para o envio das informações. Embora a sistema operacional Android esteja atualmente em sua versão 4.4 KitKat, a versão do sistema operacional Android instalada no aparelho é a versão Jelly Bean 4.1.2. No entanto, o aplicativo foi desenvolvido de modo a manter a compatibilidade com versões anteriores do sistema operacional.

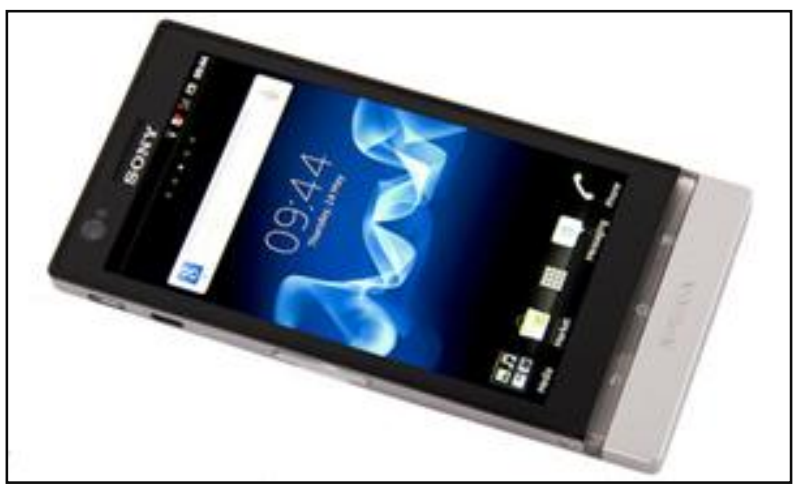

Figura 8. Aparelho Smartphone usado nos experimentos.

\subsection{Coleta de Dados}

Os experimentos foram feitos inicialmente coletando dados através do deslocamento do dispositivo pelas ruas com a aplicação em execução. São mostrados em seguida algumas imagens feitas durante o deslocamento do smartphone no trajeto de testes (Figura 9), de modo a visualizar as diferentes velocidades através das diferentes cores, como mostrado na Tabela 1.

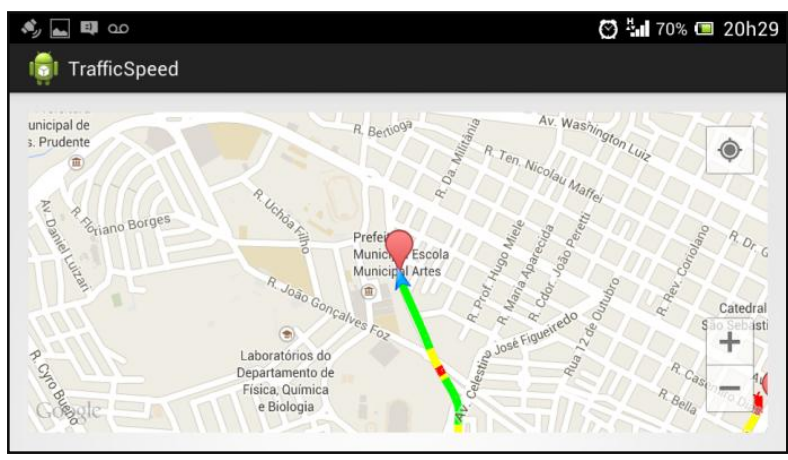

(a)

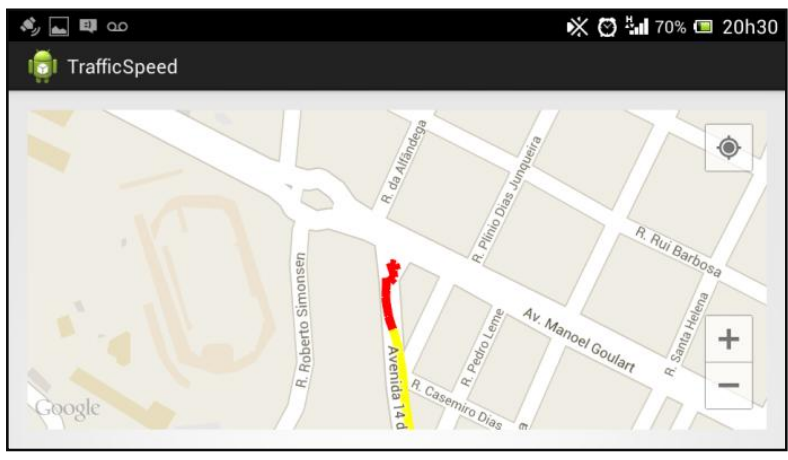

(b)

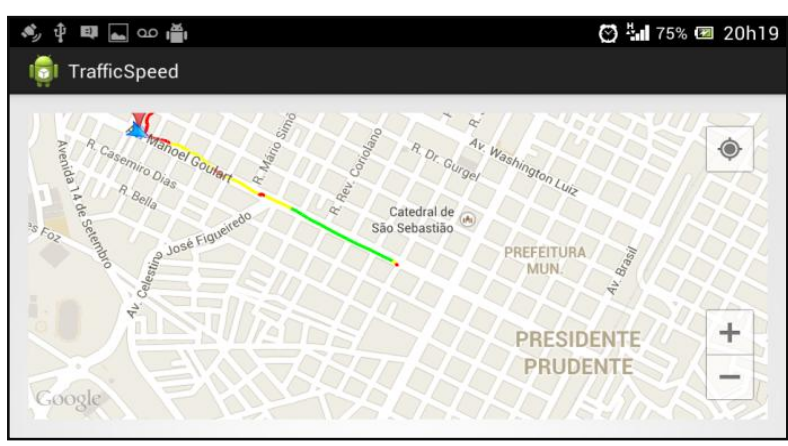

(c)

Figura 9. Coleta de dados em alguns pontos da cidade.

De modo a ilustrar esses dados, foi criado um mapa no servidor que mostra os pontos em foram feitas as leituras, como pode ser visto na Figura 10. Cada ponto mostrado na figura contém um número, o qual corresponde à quantidade de leituras enviadas naquela área. 


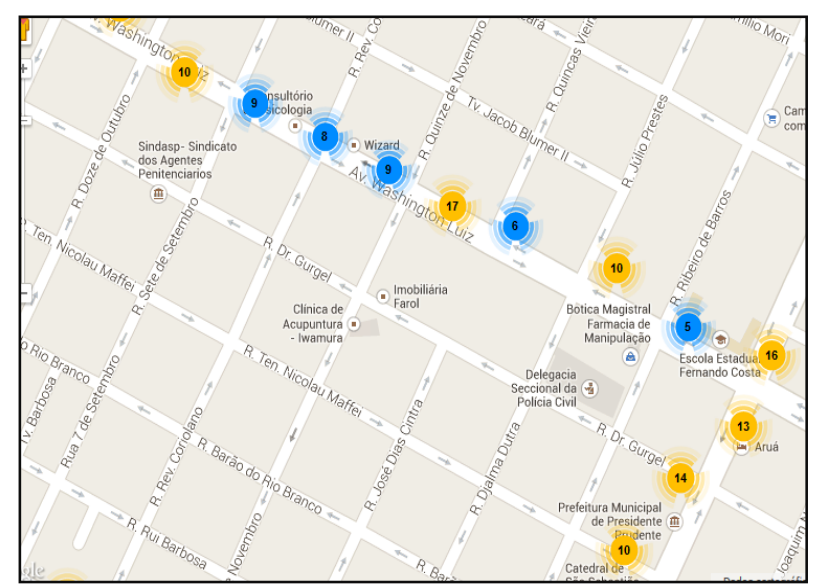

Figura 10. Quantidade de leitura por locais.

\subsection{Obtenção de rota com informações so- bre o tráfego}

Uma vez que o servidor tenha informações armazenadas a respeito das condições do tráfego, o passo seguinte é utilizar o dispositivo para recuperar uma rota utilizando as informações disponíveis para a área por onde a rota pode passar. Ou seja, são esco-
Ihidos dois pontos no mapa, uma origem e um destino, se houver informações de velocidade disponíveis entre esta rota, elas serão utilizadas na escolha das cores para a impressão dos dados da rota. Também é importante observar que ao calcular a velocidade média em um segmento da reta, o aplicativo busca os pontos que estão a uma distância máxima de dez metros deste segmento de reta, sendo ainda possível reconfigurar esta distância com diferentes valores.

A Figura 11 mostra dois pontos marcados no mapa, origem e destino da rota a ser traçada, sinalizadas diretamente no dispositivo smartphone. Estes dados são enviados para requisição da rota, e em seguida todos os segmentos de reta que compõe essa rota são processados para se obter a velocidade média obtida naquele trecho.

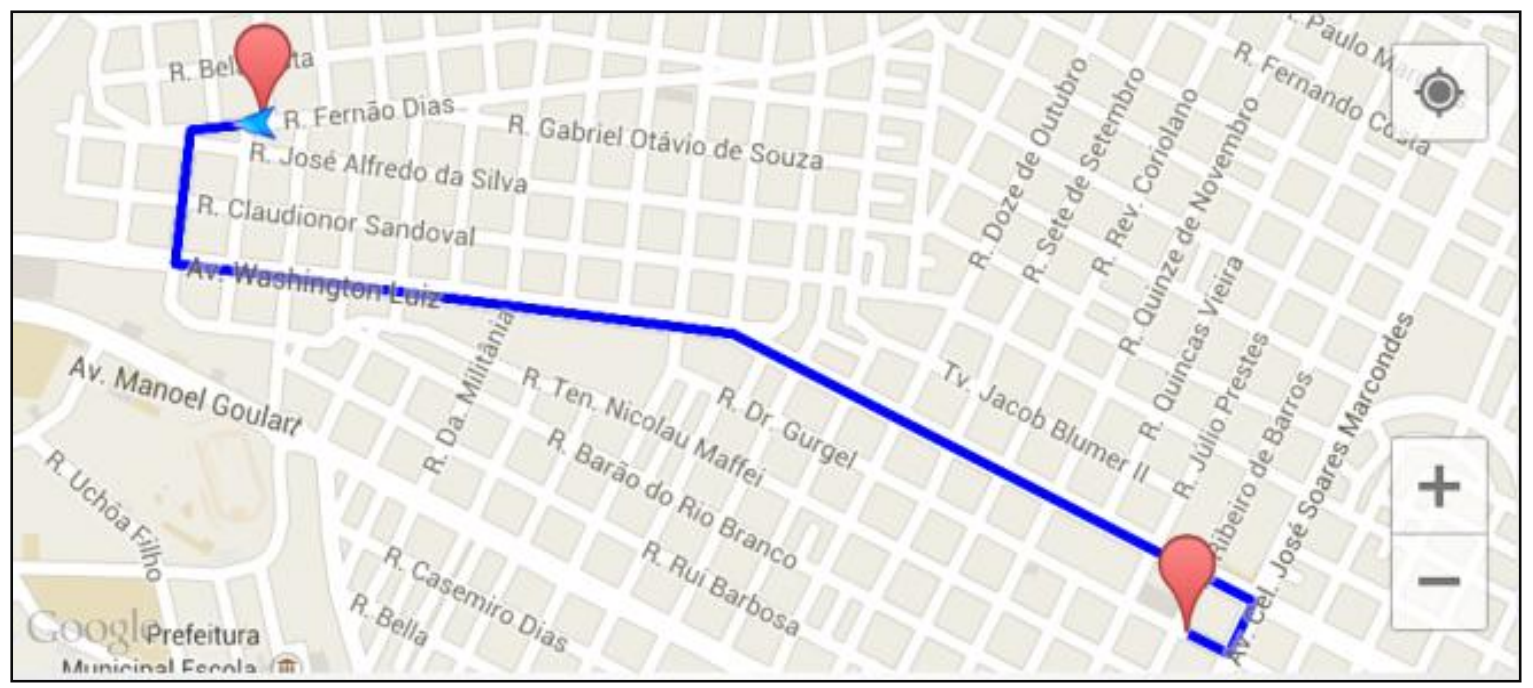

Figura 11. Rota traçada pelo Google Maps.

As coordenadas finais de cada segmento obtido que foram enviadas para o servidor e as respectivas respostas contendo a velocidade média de cada trecho são mostradas na Tabela 2. Caso não haja informa- 
ções de velocidade o servidor retorna o valor

-1 para a aplicação.

Tabela 2. Velocidade media de cada trecho.

\begin{tabular}{|r|r|r|r|r|r|r|r|}
\hline & Latitude & Longitude & Velocidade $\mathbf{~ m ~} \mathbf{~} / \mathbf{s}$ & & Latitude & \multicolumn{1}{|c|}{ Longitude } & Velocidade em $\mathbf{~} / \mathbf{s}$ \\
\hline 1 & $-22,11326$ & $-51,4049$ & 1,544652131 & 22 & $-22,11644$ & $-51,39744$ & 4,805277067 \\
\hline 2 & $-22,11332$ & $-51,40545$ & 0,84249911 & 23 & $-22,11654$ & $-51,39665$ & 6,904105425 \\
\hline 3 & $-22,11334$ & $-51,40566$ & -1 & 24 & $-22,11656$ & $-51,39656$ & 9,2544578 \\
\hline 4 & $-22,11335$ & $-51,40589$ & -1 & 25 & $-22,11658$ & $-51,39649$ & 7,678492867 \\
\hline 5 & $-22,11335$ & $-51,40589$ & 7,134701706 & 26 & $-22,11687$ & $-51,39594$ & 8,522339333 \\
\hline 6 & $-22,11355$ & $-51,40592$ & 3,923473718 & 27 & $-22,11713$ & $-51,39535$ & 9,6623471 \\
\hline 7 & $-22,11447$ & $-51,40603$ & 1,8513011 & 28 & $-22,11754$ & $-51,39448$ & 10,43162231 \\
\hline 8 & $-22,11539$ & $-51,40615$ & -1 & 29 & $-22,11796$ & $-51,39361$ & 4,426253139 \\
\hline 9 & $-22,11547$ & $-51,40616$ & 6,202666433 & 30 & $-22,11837$ & $-51,39271$ & 5,923961629 \\
\hline 10 & $-22,11547$ & $-51,40616$ & 7,134701706 & 31 & $-22,11879$ & $-51,39183$ & 8,475719517 \\
\hline 11 & $-22,11558$ & $-51,40528$ & -1 & 32 & $-22,11914$ & $-51,39106$ & 8,015232778 \\
\hline 12 & $-22,11559$ & $-51,40519$ & 0,84249911 & 33 & $-22,11919$ & $-51,39095$ & 11,620494 \\
\hline 13 & $-22,11569$ & $-51,40423$ & 6,59778176 & 34 & $-22,11961$ & $-51,39009$ & 4,393050089 \\
\hline 14 & $-22,1158$ & $-51,40324$ & 5,66958735 & 35 & $-22,12001$ & $-51,38921$ & 7,44546915 \\
\hline 15 & $-22,1159$ & $-51,40234$ & 6,217886707 & 36 & $-22,12042$ & $-51,38836$ & 7,595533144 \\
\hline 16 & $-22,1159$ & $-51,40227$ & 12,7504485 & 37 & $-22,12083$ & $-51,38746$ & 6,090344793 \\
\hline 17 & $-22,116$ & $-51,40135$ & -1 & 38 & $-22,12083$ & $-51,38746$ & 7,134701706 \\
\hline 18 & $-22,11611$ & $-51,40035$ & -1 & 39 & $-22,12166$ & $-51,38789$ & 4,880699269 \\
\hline 19 & $-22,11618$ & $-51,3998$ & 8,266224271 & 40 & $-22,12166$ & $-51,38789$ & 7,134701706 \\
\hline 20 & $-22,11623$ & $-51,39939$ & 9,4184008 & 41 & $-22,12134$ & $-51,38859$ & 6,149048883 \\
\hline 21 & $-22,11634$ & $-51,3984$ & 6,918448767 & & & &
\end{tabular}

As variações na velocidade são possíveis, pois as medições são instantâneas. Em um momento o veículo pode estar em movimento, e no momento seguinte pode estar parando em um semáforo, assim, variações de velocidade como a das linhas 12 e 13 são possíveis. O gráfico a da Figura 12 torna mais fácil a visualização da variação de velocidades, destacando a variação da velocidade em $\mathrm{m} / \mathrm{s}$ pelas leituras.

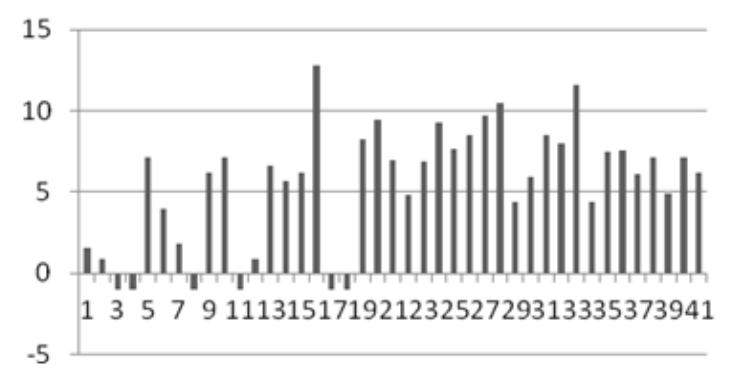

Figura 12. Variação de velocidade em $\mathrm{m} / \mathrm{s}$.
Em seguida, é possível ver na Figura 13 a mesma rota traçada no dispositivo e os critérios de cores previamente estabelecidos. Cada segmento foi desenhado com a cor referente à velocidade média obtida naquele trecho, ou em uma cor distinta caso não haja leituras próximas do segmento. É possível ainda observar na Figura 13 que diferentes medidas de velocidade média foram encontradas entre a origem e o destino da rota solicitada, sendo estas representadas com suas respectivas cores. A partir deste ponto o usuário está ciente das condições que estão sendo enfrentadas no momento na rota solicitada, cabendo ao mesmo decidir ou não por outra rota. 


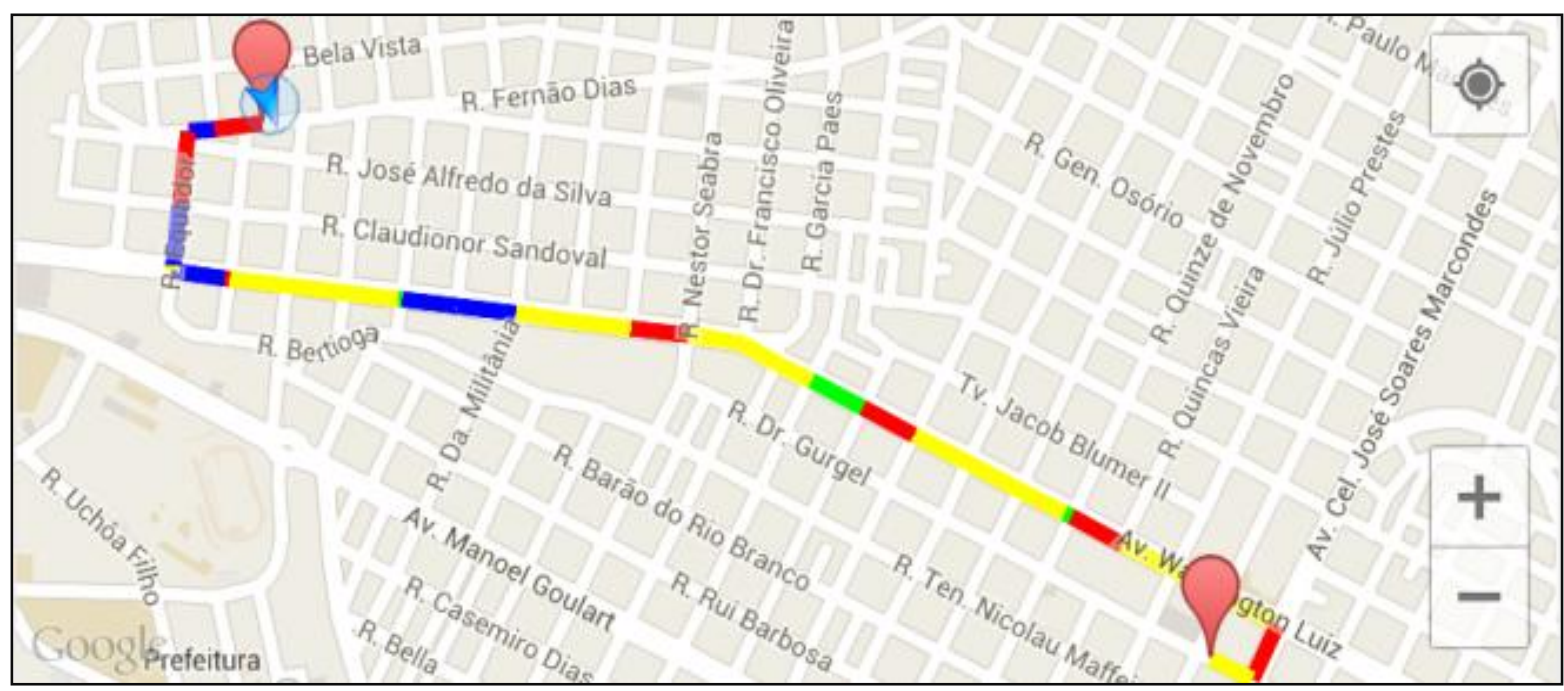

Figura 13. Rota traçada usando as leituras de velocidade para a determinação das cores.

\section{CONCLUSÕES E TRABALHOS FUTUROS}

A solução para os problemas de trânsito enfrentados na atualidade está longe de ser encontrada de forma simples e única, porém cada vez mais novas abordagens surgem com o intuito de amenizar este problema, e novas tecnologias passam a ser utilizadas como apoio ou base para essas abordagens.

Este trabalho teve o intuito de demonstrar que, uma simples aplicação colaborativa, instalada em um smartphone de um usuário comum, pode fornecer valiosas informações que podem ser aproveitadas pela própria e por outras aplicações em prol da mesma causa. A partir do momento em que tecnologias como o GPS e conexões com a internet passam a fazer parte do cotidiano da sociedade, é possível utilizá-la de forma a identificar e extrair de maneira simples, eficaz e transparente, informações essencialmente relevantes para resolução deste tipo de problema, Soma-se a isso a possibilidade de uma abordagem colaborativa, tão presente atualmente em projetos como a Wikipédia (2013), que faz com que o trabalho e os frutos colhidos sejam compartilhados.

Deixou-se claro que a tecnologia atual pode ser usada não só como apoio, mas como base para obtenção e representação dessas informações, devido à difusão destes dispositivos entre a população, e das tecnologias outrora exclusivas, que agora fazem cada vez mais parte do cotidiano. Ainda durante o desenvolvimento deste projeto surgiram diversas ideias e diferentes direções que não puderam ser exploradas devido ao escopo reduzido deste trabalho, mas que são apontadas aqui como direções para possíveis projetos futuros. Partindo do pressuposto que todos os dados obtidos através das leituras possam ser enviados para um servidor Web e armazenados, abre-se a possibilidade de se trabalhar com a união entre dados históricos, 
probabilidades, estatísticas e padrões de comportamento, de modo a antever possíveis problemas recorrentes e fornecer informações de apoio para que sejam evitados. Tais dados poderiam ser usados na decisão entre uma ou mais rotas pelo servidor, sendo que além da velocidade média sendo registrada, seriam também levados em conta os dados obtidos a partir da análise histórica dos trechos que compõe a rota. Desse modo, caminhos que tenham um histórico de lentidão em determinados períodos do ano, tais como períodos de férias ou feriados, teriam esses dados levados em consideração pela aplicação no momento em que uma rota fosse solicitada,

A Inteligência Artificial em conjunto com processamento em tempo real de grande quantidade de dados poderiam ter um papel importante na determinação de rotas a partir do sistema de GPS, o que deverá ser feito em um trabalho futuro. Imagina-se que em determinado momento um usuário faça uma solicitação de rota com origem em um ponto $A$ com destino ao ponto $B$. Dentre vários caminhos possíveis, o servidor retornaria o caminho utilizando como fatores de ponderação a distância, a média de velocidade obtida, e dados históricos de disponíveis. Entretanto, a partir do momento em que outros usuários façam a solicitação da mesma rota em um curto período de tempo, o servidor de rotas vai retornar então uma rota alternativa, que vai levar em consideração a distância, a velocidade média obtida, dados históricos, e outros usuários que estejam se dirigindo para mesma rota. Assim, o servidor de rotas seria capaz de predizer as condições em determinado trecho da rota baseando-se no fato de que já tem a informação de que outros usuários estão se dirigindo para um destino composto por rotas semelhantes.

\section{REFERÊNCIAS}

BAUZA, R. Road traffic congestion detection through cooperative Vehicle-to-Vehicle communications. In: IEEE CONFERENCE ON, 35., IEEE, 2010. p. 606-612.

BORGES, M. R. Conhecimento coletivo. In: $\mathrm{H}$. PIMENTEL, F. M. Sistemas colaborativos. Rio de Janeiro: Elsevier, 2011. p. 186-205.

CET. Companhia de Engenharia de Tráfego. Disponível em: <http://www.cetsp.com.br/> Acesso em: 06 ago. 2013.

DIGGELEN, F. V. A-GPS: Assisted GPS, GNSS, and SBAS. Norwood: Artech House, 2009.

FENABRAVE. Federação Nacional da Distribuição de Veículos Automotores. Disponível em: $\quad<$ http://www.fenabrave. com.br/>. Acesso em: 30 out. 2013.

GOOGLE TRANSLATOR. Disponível em $<$ http://translate.google.com.br/about/intl/ pt-BR_ALL/>. Acesso em: 17 nov. 2013.

GOOGLE ANDROID DEVELOPERS. Disponível em: $<$ http://developer.android.com/google/playservices/location.html>. Acesso em: 19 nov. 2013. 
KAPLAN, E. D. Understanding GPS: principles and applications. Norwood: Artech House, 1996.

LECHETA, R. R. Google Android: aprenda a criar aplicações para dispositivos móveis com o Android SDK. São Paulo: Novatec, 2013.

MONICO, J. F. G. NAVSTAR-GPS: descrição, fundamentos e aplicações. São Paulo: UNESP, 2000. 287 p.

MONICO, J. F. G. Posicionamento pelo GNSS. São Paulo: UNESP, 2008.

OPEN HANDSET ALLIANCE. Disponível em: $<$ www.openhandsetalliance.com>. Acesso em: 19 nov. 2013.
SALAMA, A. Intelligent cross road traffic management system (ICRTMS). Computer Technology and Development (ICCTD), 2010.

VIVACQUA, A. S.; GARCIA, A. C. B. Ontologia de colaboração. Sistemas Colaborativos. RJ: Elsevier-Campus-SBC, 2011. p. 34-49.

WAZE. Disponível em: <https://www.waze. com/legal/privacy>. Acesso em: 20 nov. 2013.

WIKIPÉDIA: a enciclopédia livre. Disponível em: <http://pt.wikipedia.org/>. Acesso em: 17 nov. 2013.

ZAP. Disponível em: <http://www.zap.com .br/revista/carros/cuide-de-seu-carro/gpsajuda-a-fugir-do-transito-20090515/>. Acesso em: 29 out. 2013. 